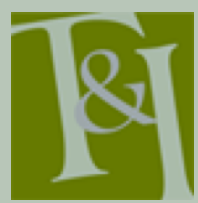

The International Journal for Translation \& In erpreting Research trans-int.org

\section{"It's good for them but not so for me": Inside the sign language interpreting call centre}

\author{
Jemina Napier \\ Heriot-Watt University, Scotland \\ J.Napier@hw.ac.uk

\section{Robert Skinner} \\ Heriot-Watt University, Scotland \\ ras3@hw.ac.uk
}

\section{Graham H. Turner}

Heriot-Watt University, Scotland

G.H.Turner@hw.ac.uk

DOI: 10.12807/ti.109202.2017.a01

\begin{abstract}
This paper reports on findings from an international survey of sign language interpreters who have experience of working remotely via video link, either in a video relay service or as a video remote interpreter. The objective of the study was to identify the common issues that confront interpreters when working in these remote environments and ascertain what aspects of interpreting remotely via a video link are working successfully. The international reach of this survey demonstrates how working remotely via video link can be an integral part of bringing about social equality for deaf sign language users; yet according to interpreters who work in these services, ineffective video interpreting policies, poor public awareness and lack of training are identified as areas needing improvement.
\end{abstract}

Keywords: video remote interpreting, sign language, interpreter experiences, interpreter perspectives, survey research

\section{Introduction}

Due to the advent of technology, an increasing number of interpreter-mediated interactions are now taking place via the use of video. Interpreters are increasingly required to be involved in: (i) video conference interpreting $(V C I)$, where there are two locations and the interpreter is in either one; or (ii) remote interpreting (RI), where all participants are together in one location and the interpreter is in a separate, remote location. In both of these situations, the communication between locations takes place via videoconference or some kind of video link-up system (Braun \& Taylor, 2011; Skinner, Napier \& Braun, in press). In the sign language interpreting sector there is also the 
potential for three different locations where participants are in two different locations and an interpreter is in a third remote location (a call centre), particularly through video relay services (Alley, 2012; Brunson, 2011).

This paper reports on findings from an international survey of sign language interpreters who have experience of working remotely via video link, either in a video relay service or as a video remote interpreter. The objective of the study was to identify the common issues reported by some interpreters who working in these remote environments, and to ascertain what aspects of interpreting remotely via video link are working successfully. The international reach of this survey demonstrates how working remotely via video link can be an integral part of bringing about social equality for deaf sign language users; yet according to interpreters who work in these services, ineffective video interpreting policies, poor public awareness and lack of training are identified as areas needing improvement.

\section{Video remote interpreting for deaf sign language users}

Video Relay Service (VRS) and Video Remote Interpreting (VRI) platforms use web-based video technology to enable deaf sign language users to communicate with (hearing) non-sign language users using their preferred language (i.e., a signed language), via an interpreter, without being physically co-located. The interpreter may be situated remotely, while the deaf and hearing persons are together in the same room (VRI), or in different locations with the interpreter in a call centre (VRS). Using the appropriate technology, the three participants are able to see and/or hear one another as required to permit spontaneous, real-time, interpreter-mediated interaction: the primary participants are able to use their preferred languages (signed and spoken), while simultaneous, bilingual, bimodal interpretation is provided to facilitate the interaction.

The delivery of sign language interpreting via video is increasing rapidly worldwide, and as a result there is a growing area of research that investigates communication through an audio-video link from linguistic and sociological perspectives (e.g., Taylor, 2005; 2009; Quinto-Pozos et al., 2010; Brunson, 2011; Napier \& Leneham, 2011; Alley, 2012; 2014; Napier, 2012; 2013; Turner et al., 2016; Napier, Skinner \& Turner, in press). Currently across the globe, the following countries have some form of video interpreting provision for deaf people: Australia, Belgium, Canada, Denmark, Finland, France, Germany, Hungary, Italy, the Netherlands, Norway, Spain, Switzerland, Sweden, the United Kingdom and the United States (Vogler et al., 2011; CSMG, 2012).

\subsection{The impetus for interpreting via video}

Locating a qualified ${ }^{\mathrm{i}}$ interpreter with the required language combination is not always straightforward or, indeed, possible to arrange. In countries where state funding is in place to support deaf people to employ interpreters, the balance of demand versus supply is of concern as the number of requests per day for a

\footnotetext{
i We take 'qualified' to mean whatever requirement is in place in a country for an interpreter to practice professionally - whether this is through completion of a college or university training course, or certification, registration or accreditation through a testing or portfolio system.
} 
qualified sign language interpreter often exceeds the number of certified interpreters available (CSMG, 2012). In countries where there is limited or no funding from the state, only a handful of qualified interpreters are available to meet national demands (de Wit, 2012). The majority of deaf people need access to an interpreter in situations in which communication with non-signers is necessary, and without government or private support most cannot afford to pay for services.

Furthermore, not all European countries have established training routes or funded work opportunities for sign language interpreters (de Wit, 2012). Without opportunities for training, coupled with lack of opportunities for work in some regions/ countries where the profession is not fully established, the pathways for individuals to develop a career in sign language interpreting are variable. This demand-versus-supply imbalance leaves many service users with a difficult choice: accept an un- or under-qualified interpreter or settle for no access. The promise of using video technology is to create a third choice: cost-effective access to a qualified interpreter remotely via video link. This is possibly the strongest rationale for moving towards video interpreting solutions, as it means that interpreters are more likely to be available quickly for short periods of time, without needing to account for travel time or costs, or the need to stipulate a minimum length for bookings (Napier \& Leneham, 2011).

Deaf sign language users identify themselves as members of a linguistic and cultural minority rather than a disability group (see Ladd, 2003; Padden \& Humphries, 1988; Senghas \& Monaghan, 2002; Napier \& Leeson, 2016). The barriers that tend to stand in their way are social attitudes and prejudice, the failure to recognise the linguistic status of sign languages, and the denial of the right to access services, businesses and public life in sign language (Batterbury, 2012; Turner, 2006). Remote call centre services could be considered as a logistically possible and cost-effective solution to overcoming some of these barriers. Legislative frameworks have played a pivotal role in recognising the rights of deaf sign language users to access services in their preferred sign language (Batterbury, 2012) $)^{\mathrm{ii}}$, and also in the expansion of video remote interpreting services for legal proceedings in particulariii (Braun \& Taylor, 2011; Vogler et al., 2011; Wheatley, 2014).

Thus the impetus for change is clear. However, simultaneous interpreting is a highly complex cognitive task (Gile, 1995; Moser-Mercer, 2003; Leeson, 2005), and therefore any modifications to an interpreter's working environment are likely to impact on their performance and how they process information.

\subsection{Video interpreting in practice: The impact on interpreters}

Video interpreting fundamentally changes the dynamics of service delivery. The most obvious change is the removal of the physical co-presence of all participants. The remote experience has been reported to impact on the effectiveness of communication via video link in a number of ways (MoserMercer, 2003; 2005; Rozinger \& Shlesinger, 2010; Napier \& Leneham, 2011).

\footnotetext{
ii Primarily the United Nations Convention on the Rights of People with Disabilities and the European Disability Strategy 2010-2020.

iii Including the European Union's Directives on Universal Service, the right to interpretation and translation in criminal proceedings and minimum standards on the rights, support and protection of victims of crime.
} 
The first is lack of 'presence': typically when interpreters are physically located with the people for whom they are mediating a conversation, they can deduce a lot of highly relevant information about the nature of the interaction and the interpersonal relationships between the participants ${ }^{\text {iv }}$. In interpretermediated video calls, however, the interpreter is separated from some or all of the participants. Being located at a distance has the potential to place the interpreter at a communicative disadvantage. An interpreter who is co-present with participants can utilise and process contextual information, such as physical characteristics, posture, gaze and facial expressions to aid their understanding and their interpreting decisions.

When the practitioner is situated in a remote location, the cues that an interpreter can typically access are less visible (Simon et al., 2010; Napier, 2013). Although a sign language interpreter would still have a sight-line with the deaf participant via the video connection, it is the ability to equally engage with what everyone else can see and hear on-site, the atmosphere in the room and other contextual information that is crucial (Braun, 2013; Braun \& Taylor, 2011; Moser-Mercer, 2003; Napier, 2013, Napier \& Leneham, 2011; NCIEC, 2008; Simon et al., 2010). Without that contextual information, the video interpreter is forced to resort to informed guesswork (Warnicke \& Plejert, 2012). The additional cognitive strain experienced by video remote interpreters has been found to result in higher subjective ratings of stress levels (Rozinger \& Shlesinger, 2010), which are known to be precursors for interpreter burnout (Wessling \& Shaw, 2014; Bower, 2015).

A second factor, which is a consequence of the on-demand expectation that users have when accessing a video interpreting service, means that interpreters have less time to prepare with callers on what is required and what will be discussed during the interaction, which is more typical of face-to-face interpreting (NCIEC, 2008; Simon et al., 2010; Gracia-García, 2002; Warnicke \& Plejert, 2012). Two surveys from the National Consortium of Interpreter Education Centers (NCIEC, 2008; Simon et al., 2010) revealed the level of difficulties that video remote interpreters in the United States (US) experience by not being able to prepare appropriately before a video-mediated call. One study found $80 \%$ of interpreters considered preparation to be essential for VRI calls, yet $67.5 \%$ of the interpreters reported that they have less opportunity for preparation in VRI calls as compared to when working in face-to-face assignments (Simon et al., 2010). In the US, VRS call centres enforce stringent procedures, which afford interpreters very little time to prepare and engage with callers to ensure the call is effective (see Brunson, 2011; Alley, 2014). The VRS standards paper produced by the US Registry of Interpreters for the Deaf (RID, 2007) is critical of this measure and advocates the opportunity to prepare for interpreting a call:

Industry standards and best practices suggest that interpreters are most successful when they are able to obtain information about the subject of an interpreted conversation in advance because interpreters exercise professional judgement and make decisions based, in part, on this information. While the FCC does not prohibit the gathering of such information by a VRS interpreter

iv See the work of Roy (2000), Turner (1995, 2007) and Wadensjö (1998) for discussions on the interpreter as participant in interaction, and how interpreters manage and coordinate interaction. Also see recent volume from Baraldi \& Gavioli (2012) on coordinating participation in dialogic interpreting. 
prior to placing a call, this is not a common policy among VRS providers. RID supports the practice of interpreters obtaining necessary information in order to process the call (RID, 2007).

The US Federal Communications Commission (FCC) provides guidelines to inform consumers on what they should expect from VRS in the United States, but many company policies go beyond these guidelines, introducing stipulations designed to minimise call time and maximise call income, which demand that the interpreters do not check the nature of the call before proceeding, clarify the relationship between the caller and the person receiving the call, or discuss the outcome of the call and determine if it was successful (Brunson, 2011; Wessling \& Shaw, 2014; Alley, 2014). This restriction does not apply if the deaf caller wishes to discuss the nature of their call and prepare the interpreter before being connected via the VRS service, but the onus is on the caller not the interpreter. A typical VRS interpreter's experience in the US is therefore highly demanding and constrained by company policies: they are expected to instantly handle calls from a nationwide range of callers, without pre-determining the topic and nature of the call, establishing particular terminology or taking time to adjust to differences in sign language dialect (Palmer, Reynolds \& Minor, 2012). The variety of video calls also places the interpreter in a position whereby they have no forewarning that a highly emotional call is likely to be made, which exposes them to potential emotional extremes (Wessling \& Shaw, 2014). Wessling and Shaw surveyed VRS interpreters to better understand how interpreters deal with such emotional extremes. What was evident in the results of their survey was that interpreters felt that no clear guidance or robust method of management existed when it came to protecting their wellbeing.

The FCC is a US-specific entity that places clear restrictions on the delivery of VRS in that country that, as can be seen from the research to date, has obvious consequences for the quality of interpreting and the interpreter experience. It is a useful reference point, however, to compare with the European context, which has a different framework for the provision of VRS/VRI services (Haualand, 2012). The US experience may not, in respect of interpreter wellbeing issues, be replicated in other countries: call centres in Europe (such as those in France, Sweden, Holland or the UK) do not necessarily impose the same regulations as described in the US. Instead, interpreters may be afforded the opportunity to engage with the deaf client ${ }^{\mathrm{v}}$ before each call takes place for as long as needed in order to conduct a successful call (personal communication, Jeff McWhinney, CEO SignVideo ${ }^{\text {vi }}$, 13 March 2014).

$\mathrm{v}$ Due to the potential variation in signing style of deaf callers, at present the convention is to prepare with a deaf client in order to assess the sign language dialect that they use, and confirm comprehension on both sides. Interpreters do not typically brief with a hearing caller as the calls are usually instigated by a deaf person to a hearing person, so there is a lack of opportunity to prepare with the hearing client beforehand. The survey question did not uncover what preparation means to the interpreter. It was kept simple because of the international variability, where some countries do not permit any form of meaningful preparation.

${ }^{v i}$ SignVideo is a UK-based private company that provides VRS and VRI through various contractual arrangements, and was the agency partner on the Insign project and thus has an overview of the various working conditions imposed on sign language interpreters working in VRS services across Europe. 
Company policies are not the only barrier to preparing for a call. Deaf respondents in the US who were interviewed about their VRS/VRI experience stated that they sometimes found it difficult or inconvenient to prepare an interpreter for certain situations (Simon et al., 2010), perhaps indicating that they did not appreciate why preparing the interpreter may be beneficial. Their reluctance to prepare interpreters may go some way to explaining why deaf VRS/VRI users in the US expect VRS/VRI interpreters to have a good level of content area knowledge, as it was assumed "good" interpreters need less preparation (Taylor, 2009; NCIEC, 2008; Simon et al., 2010). A similar response was collected from deaf citizens who participated in interviews as part of the European project reported in this paper. They expressed the desire to emulate the same experience, in terms of efficiency and ease, as callers who converse in the same language via the telephone (Turner et al., 2016).

In the past, text-relay call centres would be the only means for accessing the telephone for deaf people. Text-relay services are specialist call centres that provide a telephone caption reading and writing service, facilitated by an operator. The operator functions as a conduit between the deaf person typing and hearing person speaking, enabling live telephone interaction between a deaf and hearing person. Operators are able to communicate directly with a deaf person using a teletypewriter (TTY) machine, where messages are exchanged by manually typing onto a keyboard. Operators would convey the hearing caller's speech using the TTY and in return the operator would articulate the deaf person's typed message to the hearing participant. Deaf people often complained that calls took too long (Power, Power \& Horstmanshof, 2006; Power, Power \& Rehling, 2007), especially as callers had to specifically indicate turn-taking by stating 'go ahead' (Alley, 2012). Although video interpreting provides an opportunity for more natural conversations to occur, previous research suggests that some deaf end-users are still not clear on the role of the interpreter (NCIEC, 2008; Simon et al., 2010; Turner et al., 2016). What and who makes a good VRS/VRI interpreter has not yet been tested; there is much information to be garnered about what strategies are employed by seasoned practitioners and which interpreters are considered most effective at providing a quality VRS/VRI service.

This paper focuses on one aspect of a project that sought to investigate the efficacy of video remote interpreting services for the purposes of piloting a potential pan-European multilingual video remote interpreting service: Insign ${ }^{\text {vii }}$. Here we report on findings from an international survey of

vii Insign was a pilot project funded through Directorate General Justice of the European Commission to test the sustainability of a web-based Total Conversation platform that includes a Video Relay Service (VRS), Video Remote Interpreting (VRI) facilities and a Remote Captioning service (RCS). The overall objective of Insign was to conduct a proof of concept testing to promote independent access for deaf and hard of hearing citizens to European Institutions and their representatives. The project was led by the European Union of the Deaf (EUD) with a consortium of partners, including SignVideo (a VRS/VRI service provider), the European Forum of Sign Language Interpreters (efsli), IVèS (the platform developer), Designit (project management company) and Heriot-Watt University. Following a pan-European approach, the pilot service was made available through three demonstrations in several spoken and signed languages over a one-year period, and a mixed-methods research project was conducted in parallel in order to evaluate the viability of the Insign platform. 
interpreters who have experience of working with video relay services. The goal of the interpreter survey was to better understand interpreters' experiences when working via a video link. This is the first multi-country survey of interpreters about VRS/VRI.

The research sought to address these primary questions:

- What proportion of work do interpreters do in video remote call centres?

- What do interpreters report as being their typical work experience in a video remote call centre?

- How do interpreters manage video relay call interactions?

- What do interpreters report as the challenges that they face in mediating video remote calls?

\section{Method}

In order to examine issues raised in the literature, and seek answers to the above research questions, a questionnaire instrument was developed to collect evidence of general experiences and perceptions from sign language interpreters about working in video remote call centres. A number of respondents who provided their contact details were also invited to participate in follow-up interviews in order to discuss themes in more depth. Ethical approval to conduct the study was received from the Heriot-Watt University School of Management and Languages Ethics Review Committee.

\subsection{Participants}

Participants in the interpreter survey were 58 self-selected sign language interpreters, male and female, from 16 different countries (13 EU countries), covering a range of ages, educational backgrounds and experience. In terms of the potential sample population, it is currently estimated that there are approximately 7,500 sign language interpreters in nearly 40 European countries (de Wit, 2012), but there is no standard to determine what it means to be a qualified sign language interpreter. Furthermore, there are only 13 European countries that offer some kind of video interpreting service (Sweden, Austria, Belgium, Denmark, Finland, France, Germany, Hungary, the Netherlands, Norway, Spain, Switzerland and UK), most on a restricted level (set hours per working day) and it is a largely an emerging service. Thus the pool of potential sign language interpreters in Europe that have experience of working in VRS/VRI is likely to be no more than 200. Our sample included 37 experienced VRS/VRI interpreters: 29 were from 10 European countries. Therefore we estimate that approximately $14.5 \%$ of the potential population of sign language interpreters in Europe with VRS/VRI experience were included in the sample. A further 8 respondents with experience were from the US; the remaining 21 interpreters were from Europe and were not experienced in VRS/VRI work.

Research to date on spoken and signed remote interpreting has revealed common issues, thus as an emerging service in Europe, we expected there to be many common issues yet to be reported on from the European context, and wanted to include those respondents that did not have VRS/VRI experience. We felt that by including respondents without VRS/VRI experience, we could gauge the perceptions of interpreters as to how they feel about inevitably 
working in such a service as we see more of them established throughout Europe. Although in absolute terms 58 is not a large number of participants, as this was a survey intended to scope issues for further exploration through the Insign project, it was felt to be an adequate number for the purposes of this scoping study and adequately represented the estimated number of VRS/VRI interpreters in Europe.

\subsection{Questionnaire instrument \& interviews}

An online questionnaire instrument was developed ${ }^{\text {viii }}$ in written English (the written language expected to be most widely-understood by prospective respondents), contained a range of single-choice answers, multiple-choice answers and open-ended questions about general experience as an interpreter and working in video remote call centres, and was administered through an online survey tool: Surveyit ${ }^{\mathrm{ix}}$.

The questionnaire collected demographic information, including: (a) language background; (b) educational attainment; (c) interpreter training and experience; and (d) experiences of working with VRS or VRI. At the end of the survey, respondents were also offered the opportunity to provide contact details if they were willing to be contacted for follow-up semi-structured interviews. The interview questions focused on interpreters' experiences of working in VRS or VRI interpreting call centres and were conducted in spoken English. Thus the data collected provides the opportunity to present results both quantitatively and qualitatively through descriptive statistics. All participants involved in interviews have been provided with pseudonyms in order to preserve their identities.

\subsection{Process of recruitment}

The online survey was open to the public between February $28^{\text {th }} 2014$ and March $15^{\text {th }} 2014$. An invitation to participate in the survey was presented in International $\operatorname{Sign}^{\mathrm{x}}$ with English captions. Using network and snowball sampling techniques commonly used in interpreting research (Hale \& Napier, 2013), the invitation was disseminated through the international networks of the Heriot-Watt University research team and the Insign consortium partners (e.g., membership database of efsli, interpreter database of SignVideo), through a blog post ${ }^{\mathrm{xi}}$, and via various social media networks, such as Twitter and Facebook.

\footnotetext{
viii The survey was developed in collaboration with the international design/marketing agency and Insign consortium member, DesignIt

ix See http://surveyit.com.es/interpreters

${ }^{\mathrm{x}}$ International Sign is a form of ad hoc communication between sign language users with divergent linguistic backgrounds who do not necessarily have a common sign language. One form of International Sign is partially conventionalized and functions as a lingua franca in international Deaf communities, in particular in the context of meetings and conferences of international deaf organisations (Rosenstock, 2016). International Sign is increasingly used to convey information to international Deaf communities through websites and as part of research projects (Rosenstock \& Napier, 2016).

xi See https://lifeinlincs.wordpress.com/2014/03/07/insign-breaking-new-ground-invideo-remote-interpreting-research
} 
There is a patchwork of VRS/VRI provision across the countries represented, and this needs to be described in order to contextualise the data. In Europe, providers do not distinguish between VRS and VRI (CSMG, 2012; Haualand, 2012). In the US, only VRS services are funded by the government 24 hours a day/ 7 days a week (in accord with Article IV of the American Disabilities Act [CSMG, 2012]), with the aim of making telephone networks functionally equivalent for all citizens (see Brunson, 2011). However, VRI services in the US are arranged privately with commercial providers. Elsewhere, Australia, Belgium, Finland, Germany, Hungary, Italy, Norway, New Zealand, Sweden, Switzerland, and Spain all provide a state-funded national video interpreting service (ETSI, 2009; Vogler et al., 2011; Åström, 2012; CSMG, 2012). Operational hours and conditions of use vary among these countries. In Denmark, France and the UK, VRS/VRI providers are private commercial enterprises that supply video interpreting services to companies, organisations or individuals (CSMG, 2012). Operational hours and conditions of use also vary between these three countries. No VRS/VRI service is available to deaf people in Albania, Luxembourg and Croatia.

Here we present a descriptive statistical overview of the results from the questionnaire, along with qualitative extracts from interviews in order to elucidate on the survey findings. First we provide demographic details of the respondents before detailing the findings of the survey and interviews.

\subsection{Demographics}

In total 155 interpreters took part in the online survey; 58 fully-completed responses are included for analysis in this paper. The largest contingent of respondents were from the UK $(24.1 \%)$ followed by the US $(13.8 \%)$, Germany (8.6\%) and Spain (8.6\%). Other nationalities included Italy, France, Norway, Finland, Sweden, Croatia, Luxembourg, Switzerland, Albania and Hungary, who were represented by only one or two respondents. Forty-six interpreters were from within the EU (79.3\%). The sample group sizes were too small to detect any statistical differences in responses by nationality, age, gender or experience.

Almost all of the respondents were qualified/certified interpreters $(83 \%)$. Many had achieved their qualified/certified status via an academic training route $(15.5 \%$ held a master's degree; $5.1 \%$ held another post-graduate qualification; $20.7 \%$ held a bachelor's degree) while nearly a quarter had done so via a vocational training course $(23 \%)$. The majority of respondents were women $(86 \%)$, with an average age of 40 years old. On average respondents had been practicing as interpreters for 13.3 years ( $\mathrm{SD}=10 \mathrm{years}$ ), with twothirds being non-native signers $(66.7 \%)$. The non-native signers had been signing for a considerable number of years (mean 16.7 years; $\mathrm{SD}=9.5$ years). Half of all respondents had been practicing as interpreters for more than 10 years. Thirty-six per cent of the interpreters who took part in the survey also taught interpreting, including $90 \%$ of those respondents over the age of 35 years.

\subsection{Language skills}

The ideal for a pan-European multilingual interpreting service would be for interpreters to work between more than one language pair. We therefore investigated what other languages European sign language interpreters knew. 
When comparing the mean scores between spoken and sign languages used, EU-based interpreters know more spoken languages than signed languages (mean=1.6 spoken languages, mean=1.2 sign languages). Native signers tend to know more sign languages than non-native signers (native mean $=1.9$ sign languages, non-native mean $=1.1$ sign language), with $35 \%$ of native signers also being familiar with International Sign as well as their native signed language ${ }^{\mathrm{xii}}$. In terms of working languages, nearly a third of the interpreters who participated in the survey know and work with British Sign Language (BSL) (28.3\%). The second largest group knows and works with International Sign (15.2\%), and the third largest German Sign Language (DGS) (13\%). These results should be interpreted cautiously given that, as noted earlier, $30.4 \%$ of EU respondents were British and speak English exclusively, and $100 \%$ of those respondents work with BSL.

In this survey, almost $70 \%$ of EU-based respondents speak English, with $62.5 \%$ of non-British respondents from the EU speaking English as well as their mother tongue. The British respondents know only one spoken language: English.

\subsection{Work profiles}

The next theme focused on interpreter respondents' typical domains of work and how often respondents worked as interpreters in different domains throughout the week.

The most common working domains for respondents were: workplace/ office environments $(75.9 \%)$, higher education $(74.1 \%)$, conferences $(69 \%)$, Deaf community events $(65.5 \%)$, health $(63.8 \%)$, arts and culture $(50 \%)$, political domains $(46.6 \%)$, social care $(46.5 \%)$ and police/legal contexts $(34.5 \%)$. Only a third of respondents regularly worked in VRS/VRI settings $(34.5 \%)$. This may be indicative of the extent to which VRS/VRI is offered in their country.

The vast majority of respondents worked four $(17.3 \%)$ to five $(60.3 \%)$ days a week, while $13.8 \%$ worked for between one and three days per week as an interpreter.

\subsection{VRI/VRS experiences and perceptions}

Approximately $74 \%$ of interpreters understood the differences between VRS and VRI. When comparing regions, 70\% of EU-based interpreters knew the distinction, but outside the EU, a larger proportion (91.7\%) of interpreters better understood this distinction. This result is possibly reflective of how provisions are legislated for in the US, as all VRS calls are paid for by the state and all VRI calls are rebilled to the caller. Although we did not analyse for statistical significance, the results revealed that a higher percentage of older interpreters and native signers from the EU stated that they understood the differences between VRS and VRI.

In relation to their actual experience of working with VRS or VRI, $63.8 \%$ of the interpreters had at some point in their career worked with VRS services

\footnotetext{
xii At the time of research there was no official mechanism to recognise the status of an IS interpreter. There is now the official World Federation of the Deaf-World Association of Sign Language Interpreters accreditation process (See https://wfdeaf. org/who-we-are/wfd-wasli-international-sign-interpreter-accreditation/). The purpose of the question about IS skills in the survey was to gauge the possibility to increase language combinations the EU/EC may require to meet obligations.
} 
and/or VRI $(n=37)$. Interpreters who had already worked in this domain tended to be older and to be native signers.

\subsubsection{Experience working in VRS/VRI}

The data reported in this section focuses on the 37 (63.7\%) interpreters who had some experience working in video remote call centres.

The respondents represented a broad mix of inexperienced to highly experienced video interpreters (mean $=4.6$ years). Over $40 \%$ of the respondents had under two years' experience in the video interpreting field (one year, $16 \%$; two years, $21.6 \%$ ) while the rest $(62.4 \%)$ reported between three and 15 or more years' experience of VRS/VRI interpreting (3-4 years, 19.2\%, 5-6 years, $18.9 \%$; 7 years, $8.1 \%$, 10 years, $10.8 \%, 15$ years, $5.4 \%$ ).

When comparing the hours per week that interpreters usually worked within VRS and VRI settings, it is clear that interpreters were handling more VRS than VRI calls (see Figure 1). Interpreters rarely spent more than two hours per week handling VRI calls (mean=1.4 hours per week; $\mathrm{SD}=1.8$ ) while VRS calls were more sporadic at between 3 and 20 hours per week (mean=6.1 hours per week; $\mathrm{SD}=6.6$ ).

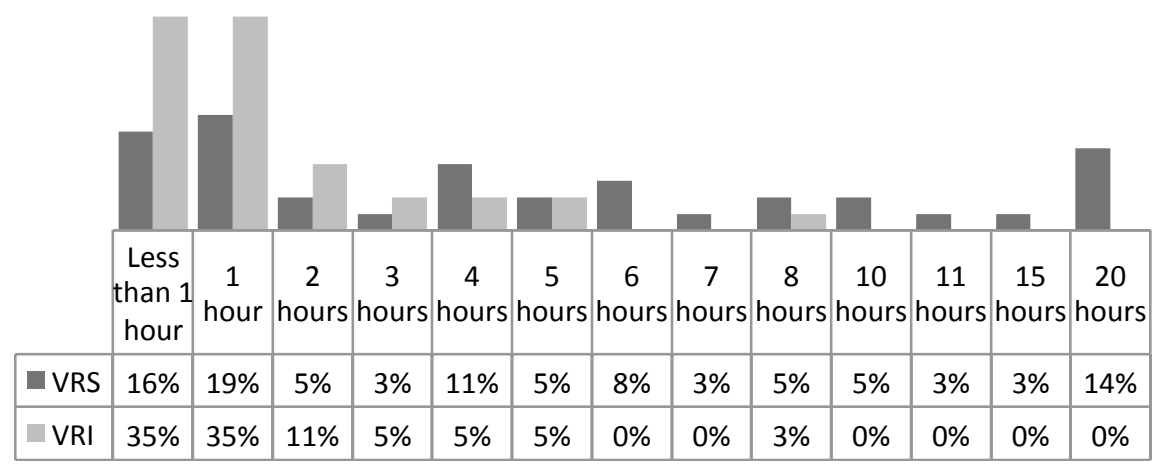

Figure 1: Hours per week handling VRS and VRI calls

Preparation is recognised as an essential aspect of an interpreter's practice (Russell, 2008; Nicodemus et al., 2014) and, based on research in North America, opportunities to prepare are inconsistent (Simon et al., 2010). It would appear that respondents who worked in call centres often take one minute to prepare for a VRS/VRI call (38\%), but a few respondents stated that it took as long as 30 minutes (see Figure 2). The average length of time for call preparation is 4.1 minutes ( $\mathrm{SD}=6$ minutes). The interpreting of a call itself, however, typically takes an average of 14.4 minutes ( $\mathrm{SD}=13.5$ minutes) (CSMG, 2012). Opportunities to prepare for a call appear to be brief: this is a concern often highlighted by interpreters throughout the survey results. 


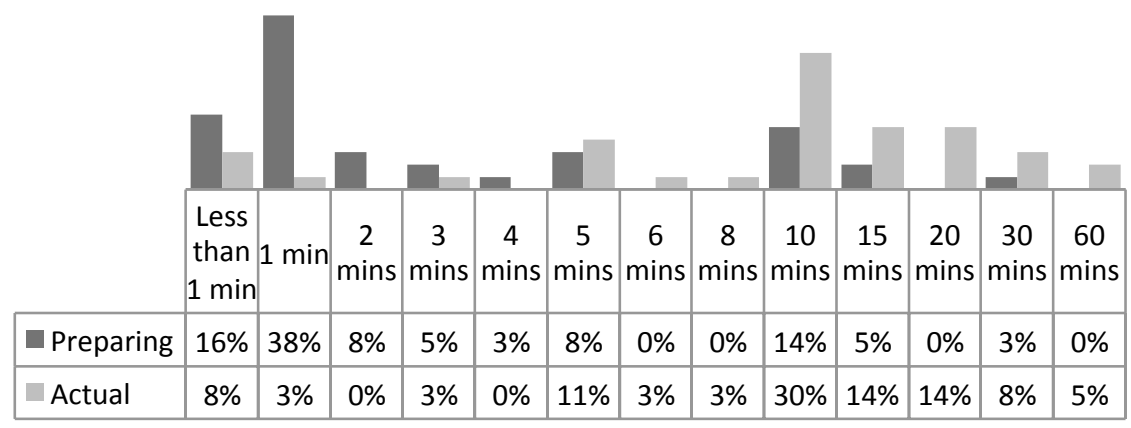

Figure 2: Average time spent preparing for a call and average time spent interpreting a call

\subsubsection{Interpreter perceptions of VRS/VRI}

We asked all 58 interpreters to rate on scale of 1-5 (1 = "doesn't help at all" through to $5=$ "They're extremely helpful") how they felt about working with technology in their interpreting practice.

When asked to rate how much benefit VRS/VRI brought to their interpreting practice there was a mixed response from interpreters. Fifty per cent responded positively towards the rise of video-based services. Forty per cent of respondents felt VRS/VRI technologies hindered their work in some way (see Figure 3). Open-ended survey comments suggest that interpreters prefer on-site interpreting and are wary of working with technology:

"No face-to-face situation, so there is no feedback from the deaf client. I do not trust the technology [Internet etc.]. Deaf people do not always know how to behave while being on the phone [is it my responsibility to teach it to them?]." (Lena, Austria)

"Does help the accessibility for clients, not for the interpreter." (Ana, Germany)

"I can see they are helpful for clients but from my lack of understanding, I feel that communication in 2D is inferior therefore how can it 'help' our work." (June, UK)

Thus it would appear that the drive to expand video-based interpreting provision is not unanimously agreed upon among interpreters. This uncertainty is shared with spoken language interpreters where many value onsite working conditions as opposed to the unpredictable or artificial environment created by technology (Braun, 2013; Moser-Mercer, 2003). The 58 interpreters in our survey were asked to explain why they felt VRS/VRI services helped or hindered their work (see Figure 3). 


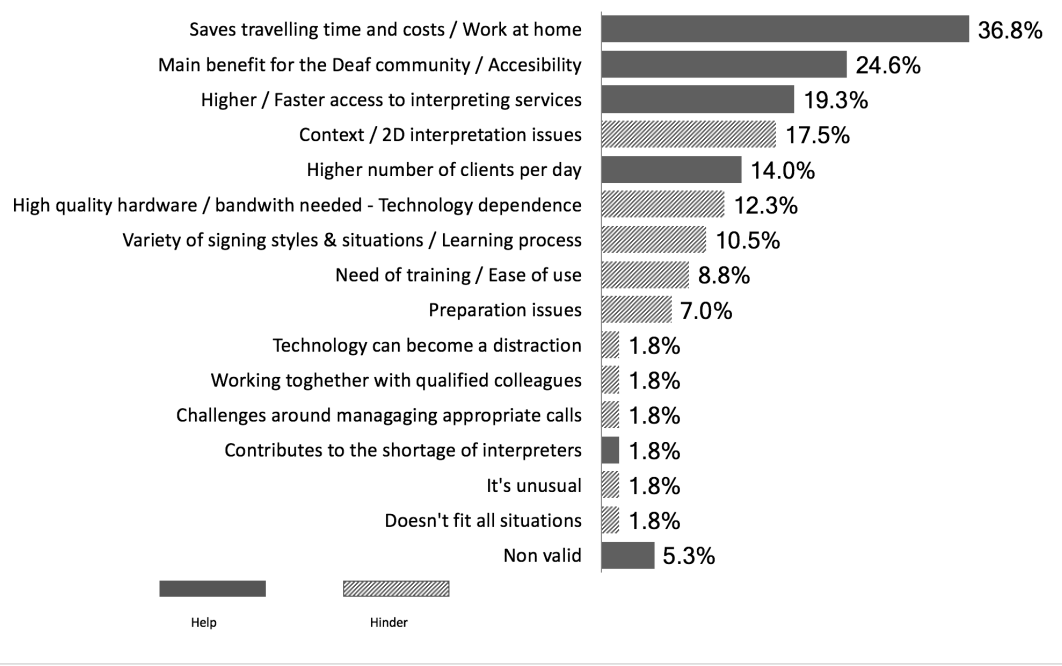

Figure 3. How do VRS/VRI technologies help or hinder your work?

There are three main reasons why respondents believed VRS/VRI services help interpreters. The ability to save time and travel costs $(37 \%)$ was a popular explanation, followed by benefit to Deaf communities $(23.9 \%)$ and recognising the benefit of immediate access to an interpreter (19\%). Interpreting via a web-based platform is often hailed as a solution to the imbalance between interpreting supply and demand. The most popular option "saves travel time and costs" is not only a benefit for the interpreter but also means that offering VRS/VRI maximises the opportunities for deaf people to access qualified interpreters on demand. The benefit is ultimately meant for the end user not the interpreter. Below is a selection of comments taken from the interpreter survey responses that confirm the benefits of VRS/VRI services:

"The variety of calls and callers gives interpreters a formidable push to grow professionally. The equivalence in time spent interpreting from BSL to English and from English to BSL means we [have to] polish our skills both ways." (Juliet, UK)

"The platform I use to perform VRI/ VRS duties is easy to use and intuitive, so that part of the role is simple. Occasionally one faces technical issues, which can be a challenge to resolve however, if the interpreter has technical competence and is comfortable solving those issues, or can easily refer them on to IT support, then they'll never be too much of a hindrance for the interpreter. High-quality hardware such as monitors and WebCams and increased broadband speeds have given way to good quality screen resolution, so now, overall picture is very good. Sometimes a deaf customer may have contention on their bandwidth and the interpreter may have difficulties seeing the customer, when this happens interpreting can be a challenge. Sometimes, I find my lack of presence in certain VRI calls a challenge, this may be because I'm unable to see any of the hearing participants and the visual clues that I would normally gather when I'm physically in a meeting interpreting are not available to me, and would often aid my interpretation." (Gail, UK) 
"In a country with a lack of interpreters and long distance between interpreter assignments it saves time. You can also have an interpreter there in no time at emergency -hospital... The most important [thing] is to overcome the distance between the interpreter and the people that want to talk to each other. Might work in conferences and educational settings as well." (Barbara, Sweden)

"I think it's good as it empowers the Deaf community to access goods and services and also means that interpreters are able to service a greater number of Deaf clients." (Nicky, UK)

The three most typical issues that negatively impact on the interpreter's ability to function in a video remote call centre are: (1) reliance on a twodimensional (2D) format which can impair sign language comprehension $(17.5 \%),(2)$ technological capabilities and reliability (12.3\%) and (3) having to interpret for a wide variety of deaf caller signing styles $(10.5 \%)$. It is evident that interpreters think the service is undoubtedly a beneficial technology for deaf users; as some indicate, though, this does not necessarily mean that the service is also beneficial for the interpreters themselves.

The next question required respondents to focus on the main types of problems they encounter when working in VRS/VRI settings. Nearly half of the respondents noted the short time available to prepare for the call (this was only a concern for $7 \%$ of respondents in the previous question). This was followed by difficulties inherent in the use of technology itself (see Figure 4). Another factor that many interpreters perceived as an issue was the difficulty found in building rapport with clients when interacting from a remote location (i.e. the lack of proximity). This finding supports results from studies in Australia in courtrooms (Napier, 2012; 2013; Napier \& Leneham, 2011). Finally, another concern of interpreters pertains to end-users' lack of awareness about how VRS/VRI works. This concern was also raised by deaf users surveyed about video remote interpreting as part of this project (see Turner et al., 2016). Hearing people who use the service are often the least experienced participant, who hold little to no prior experience of using an interpreter or a telecommunication relay service. Therefore, accommodations need to be made to support the hearing participant with how best to make or receive a call via an interpreter. Both interpreters and deaf respondents shared the view that it is difficult to convey information to hearing 'naïve' users about a complex method of communication in a short space of time.

Further to the question addressing perceptions of whether technology is a help or a hindrance to their interpreting work (as shown in Figure 3), the next question honed in on the positive and negative aspects of video remote interpreting and respondents were invited to select three positive aspects and three negative aspects (see Figure 4). 


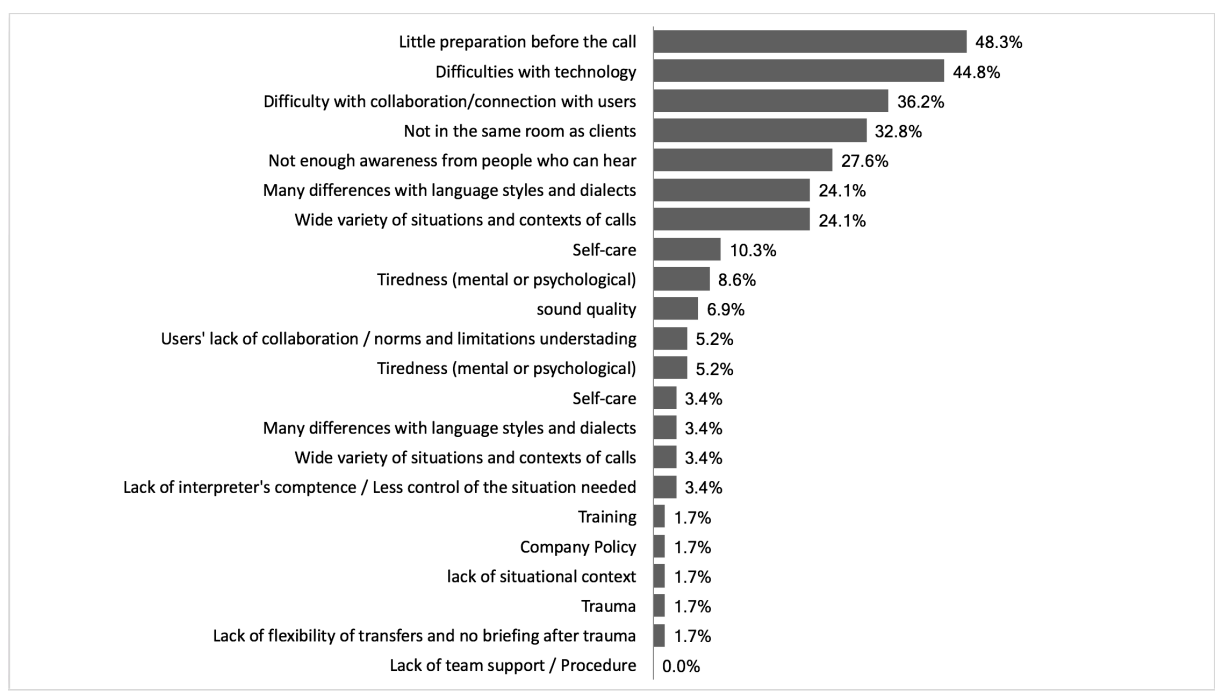

Figure 4: Positive and negative aspects of working in VRS/VRI settings

It can be seen that the aspects rated most highly (from $24.1 \%-48.3 \%$ ) are predominantly negative, in that they outline the challenges faced by interpreters in mediating video remote calls. Respondents were given the opportunity to provide open comments in relation to negative aspects of the work, and the comments below are illustrative of the typical comments received:

"Less control of the situation, like interruptions by the interpreter are ignored. Turn taking is different, interpreters should learn this, interpreter might have less control in turn taking which can set the deaf person make in power [sic] to contribute to the conversation." (Celest, Netherlands)

"Lack of understanding of the process on either side. Lack of situational context." (Emma, Netherlands)

"Poor use, e.g. trying to do a meeting using an iPhone, and phone microphones, specialist vocab in calls, especially teleconferences." (Mike, UK)

"Deaf person not understanding hearing norms for telephone etiquette or webcam limitations" (Karen, UK)

"Managing expectation from deaf caller e.g.: Some deaf callers have never used VRI/VRS before and usually need briefing on how conduct a call and may require more cultural mediation during the call in order for the call to be a success." (Gail, UK)

Interpreters who had prior experience of working in VRS/VRI $(n=37)$ were asked to rate what improvements VRS/VRI services should prioritise in order to ensure quality services (see Figure 5). The experienced interpreters generally felt the most important areas to address were in relation to education/training and technology. The survey comments from interpreters reinforce the need for better quality audio/video (57.1\%) including reliable network and hardware solutions (39.3\%). The training of interpreters (39.3\%) was considered a higher priority than the recruitment of experienced interpreters $(3.6 \%)$, respondents felt the focus should be on customer service 
skills for interpreters $(28.6 \%)$ and the ability to garner more contextual information before interpreting a call $(21.4 \%)$. Educating users about how and for what purposes they can use VRS/VRI services (67.9\%) was deemed necessary.

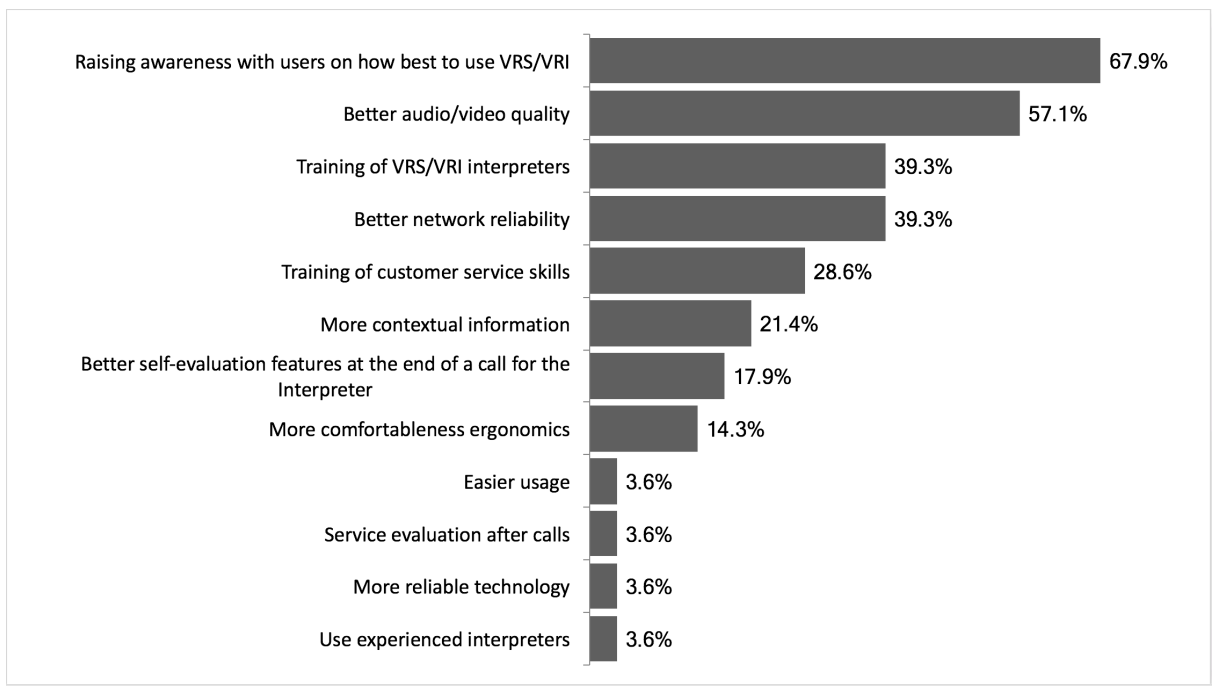

Figure 5. What improvements should VRS/VRI services prioritise?

We found it interesting that the interpreters with experience of working in video remote call centres did not, on the whole, report that it is important to use experienced interpreters, which is a somewhat surprising finding given the inherent challenges that interpreters appear to face when working in video remote call centres. Typically it is recommended that any particularly challenging work should be undertaken by experienced interpreters, for example in legal settings (Hale, 2004; Roberson, Russell \& Shaw, 2011; 2012).

Generally when the interpreters were asked to rate their satisfaction with VRS/VRI technologies, respondents were on the whole inclined to be satisfied (very satisfied $=29.7 \%$, neither satisfied or not satisfied $=51.4 \%$ ), with fewer than one-fifth $(18.9 \%)$ declaring themselves "not satisfied at all". Although the overall experience could be described as positive, it would appear that there is still room for improvement in VRS/VRI services from the interpreter's perspective.

\section{Discussion}

The survey attracted responses from a number of interpreters from around the world, with a high ratio of experienced interpreters who completed the survey (50\% have been part of the profession for more than 10 years, with more than 15 years of experience in using signed language). Only $15-16 \%$ had fewer than four years' interpreting experience. In general, the interpreters who participated in the survey demonstrated a reasonable to high level of experience as interpreters, with a large proportion having been professionally trained, or having their full professional interpreter certification.

Translation \& Interpreting Vol 9 No 2 (2017) 
From this pool, 37 of the 58 interpreters had personal experience of working in VRS/VRI settings. As explained earlier, the provision of video interpreting services varies from country to country ${ }^{\text {xiii }}$, and the political situation in different countries can impact on how each service is structured and distributed (Haualand, 2012).

The data from interpreters found that $43.2 \%$ have between five and 15 years' experience working in VRS/VRI settings, and handle on average 6.1 VRS hours per week (equivalent to half a day per week) and 1.4 VRI hours per week. Call centres in the EU tend to treat all VRS and VRI calls within the same framework (i.e., there is no requirement to specify whether the call centre provides VRI or VRS). Only $69 \%$ of EU interpreters, compared to $92 \%$ of non-EU interpreters, know the difference between VRS and VRI. In the US, VRI services are not funded by the state (FCC, 2016), as VRI is regarded as a need outside the scope of telephone 'functional equivalence'. Therefore, VRS interpreters working in call centres are expected to understand the difference and only accept VRS calls (Brunson, 2011). However, as this distinction is not made in Europe, this may explain why less EU interpreters understand the difference between VRS and VRI as it is not an important aspect of their work.

Video-based services for deaf people are still relatively new for some European countries. Therefore, to conduct calls with an interpreter with whom they are personally unfamiliar is a new experience for many deaf people. Typically, deaf people would prefer to use an interpreter they already know (Turner et al., 2016). Video remote interpreting services offer deaf people the freedom to access telephone networks as and when needed. The interpreters' responses to our survey suggest that deaf callers are not always fully aware of how hearing people typically interact via the telephone, under what conditions hearing people use the telephone, and how to work with unfamiliar interpreters. In addition, deaf callers could be initiating a call to, or receiving a call from, a hearing person who has never had contact with a deaf person before. The hearing person is therefore more likely to be unversed in how to communicate via an interpreter, and/or with a deaf person. The fact that interpreters state that hearing people need to be educated about receiving VRS/VRI calls from deaf people supports the comments made by deaf people about the need to raise awareness generally (Lewin et al., 2009; Turner et al., 2016).

The survey results reveal that the average duration of video interpreted calls is around 14.4 minutes with more than $50 \%$ of interpreters having less than two minutes to prepare for the call. Although the results here resonate with the interviews and survey data collected from two US studies (NCIEC, 2008; Simon et al., 2010) and research on professional autonomy in call centre settings (Alley, 2014), it would appear that in the European context interpreters are more able to prepare for calls with deaf callers and there are less time limitations than experienced in the US. Being able to prepare for calls may help interpreters to deal with dialectical variation in signing and signing style idiosyncrasies, which can occur when having to take calls from all over a country rather than just the local area where you are based (Palmer, Reynolds \& Minor, 2012). It is interesting to note however, that interpreter

xiii That is, some countries have nothing, others only have one provider, while others have several.

Translation \& Interpreting Vol 9 No 2 (2017) 
respondents did not raise the same need to prepare with hearing callers, who may also use dialectical or idiosyncratic speech.

Some of the interpreters participating in this survey were able to engage in some form of preparation (22\% have 10-30 minutes of preparation per call). It does seem that interpreters have some professional autonomy when handling calls, but it would appear that the current average preparation time indicates the level of autonomy is minimal. Although preparation time is deemed important for ensuring call quality and to safeguard interpreters' ability to provide accurate renditions of caller comments (personal communication, Jeff McWhinney, CEO SignVideo, 13 March 2014), ultimately giving interpreters the autonomy to handle calls and determine the amount of preparation time needed for each call has implications for the cost of service delivery.

The data collected here is based on interpreter self-reports so further research would be needed to investigate actual duration of preparation time, how this initial contact is used by all participants, and the difference made to the actual call experience.

As described above, preparation is not always possible for VRS/VRI calls, and is dependent on the caller's willingness to divulge information. Results from a survey of deaf end-users as part of the Insign project showed that interviewees were generally reluctant to provide background information because making a call is unpredictable and things might not always go to plan (Turner et al., 2016). Instead, deaf callers prefer to reach an interpreter who has good contextual knowledge and can manage their call with the least additional input. This conflict of needs may explain why $21.4 \%$ of interpreters consider more contextual information about a call is a priority for improving video-based interpreting services. Further research is needed to verify if a more experienced interpreter can perform just as well in mediating a VRS/VRI call with little (or no) background information.

Interpreters were asked to consider the difficulties they would feel most affected by when based in a VRS/VRI centre. Lack of opportunities to prepare and working with technology were concerns for almost half of the respondents $(48.2 \%$ and $44.8 \%$ respectively), followed by difficulty collaborating/ connecting with users $(36.2 \%)$ and being in a different location to the clients $(32.8 \%)$. Again, a similar response was observed in the Simon et al. (2010) VRI survey and NCIEC (2008) VRS survey. Many of these concerns are interconnected. With a robust video and audio connection, the interpreter is more at liberty to focus on the call itself rather than 'educating' callers about how the process works. This final point may explain why $67.9 \%$ considered raising awareness as a necessary step to improving the delivery of video interpreting services. Other improvements needed include better audio/video quality (57.1\%) and training of interpreters (39.3\%).

Diagnosing and resolving technical issues are inevitable parts of the video interpreter's role and knowing the basic steps can be beneficial. However, it is clear that the web-based system is vulnerable to technical glitches, which can impact on the delivery of a service. This helps to explain the mixed satisfaction levels interpreters have towards working with current VRS/VRI technologies: one group in the survey have a strong dislike of the technology $(29.7 \%$ ), while $51.4 \%$ were neutral and $18.9 \%$ interpreters were satisfied with VRS/VRI technologies. None of the interpreters were "very satisfied', an indication that the platform requires further improvement. All of the concerns listed above were also identified by Taylor (2009) in her study of 
US-based VRS interpreters, and feature in the list of her recommendations as areas for further improvement.

\section{Limitations of the study}

Before presenting our conclusions and discussing the implications of the findings, it is necessary to acknowledge the limitations of the study. There are several reasons why the findings of this study may not be readily generalized:

Firstly, the sample of 58 survey respondents is a small number for a multi-country study. It is impossible to gauge the estimated population of professional sign language interpreters inside and outside the EU, but given that this is the first study of its kind that crosses country boundaries in relation to VRS/VRI specifically, and that VRS/VRI work is still an emerging area in the European sign language interpreting profession, it can be considered as a preliminary snapshot of interpreter experiences.

Secondly, as respondents were self-selected, it is possible that people who have had particularly positive or negative experiences of working in VRS/VRI settings would make the effort to reply to the survey, which may affect the results.

Thirdly, we recognise that administering a survey in English across several countries is not ideal for collecting data from people who work with other languages. So again, the sample may not be representative of the range of interpreters working in VRS/VRI interpreting settings, as only those interpreters comfortable enough with English would have been willing to respond to the survey. Ideally, the survey should have been be made available in several written languages, however, the creation of multilingual surveys has its own inherent challenges in ensuring all versions are created or translated accurately to retain the integrity of the questions, and back translations of responses can be time consuming (Salaets \& Böser 2015; Leeson et al., 2017).

Finally, one-third of the respondents also taught interpreting. It could be argued that this is not true of the overarching field of VRS/ VRI interpreting, but may only apply to particular countries. Those who are qualified or involved in training are more likely to respond to a research study due to valuing academic explorations of interpreting. It is also possible that this might have had an effect on the responses (e.g., respondents providing the "textbook" response rather than one that would be generated by someone who is not formally involved in the education of other interpreters). This is difficult to judge, but should be taken into consideration.

\section{Conclusions}

This online survey collected data from 58 interpreters across 16 different countries and found that generally interpreters can see the benefits of providing VRS/VRI services, both for themselves as practitioners and also for Deaf communities.

Video remote interpreters who have had training in how to handle calls and who have locally based support systems can provide an effective videobased service. The success of the service is dependent on particular conditions being met first. The considerations must take account that interpreters based remotely must regularly cope with unpredictable, spontaneous on-demand 
pressures from callers, a wide range of topics to interpret, call management complications, and idiosyncratic communication styles (Wessling \& Shaw, 2014; Palmer, Reynolds \& Minor, 2012). Collectively, these factors can impact on how well a video interpreter performs and how long they continue to work as a VRS/VRI interpreter (Bower, 2015). Training is needed to ensure that everyone who is involved in the communication exchange does what they can to share effectively the responsibility for producing a successful call.

In summary, we return to our research questions and find that (i) interpreters still predominantly do most of their work in face-to-face community settings, but it appears that the amount of time spent working in video remote call centres is growing; (ii) interpreters report that their typical work experience in a video remote call centre is satisfactory but that there are challenges faced due to interpersonal and technological issues; (iii) interpreters manage video relay call interactions by ensuring that deaf and hearing callers understand the process; and (iv) interpreters report that the challenges they face in mediating video remote calls primarily relate to technological glitches, not being able to sufficiently prepare calls and therefore misunderstanding deaf signers, or hearing call receivers not understanding the process of taking a call from a deaf person through an interpreter. Ultimately, the interpreters in this study recognise the value of the provision of video-based interpreting services for Deaf communities, but suggest that although the establishment of such services meets the needs of deaf sign language users, their experiences of working in a video remote call centre are not always positive.

We can see that the landscape of sign language interpreting practice is changing with the advent of video remote interpreting services, and in some circumstances are changing rapidly, for example the Scottish Government recently commissioned the provision of a video-based interpreting service for deaf sign language users in Scotland to access public institutions such as health and legal services ${ }^{\text {xiv }}$. Thus we would recommend that there is a need to evaluate any new developments in VRS/VRI provision in light of the findings of the Insign project, taking into account the experiences and perceptions of VRS/VRI as reported by interpreters in this study, particularly in relation to working conditions and training needs.

\section{Acknowledgements}

This study would not have been possible without funding from the European Commission DG Justice and the support from our consortium partners, particularly DesignIt for access to the survey tool and assistance with analysis of results, efsli and SignVideo for dissemination of the invitation to participate in the survey to sign language interpreters throughout Europe, and the personal and professional networks of all consortium partners. We would also like to acknowledge the input of all the survey respondents. We are grateful for your time and significant contribution to helping us understand your experiences of working in VRS/VRI settings.

${ }^{\text {xiv }}$ See http://contactscotland-bsl.org 


\section{References}

Alley, E. (2014). "Who makes the rules anyway?" Reality and perception of guidelines in Video Relay Service interpreting. The Interpreters Newsletter, 19, 13-26.

Alley, E. (2012). Exploring remote interpreting. International Journal of Interpreter Education, 4(1), 111-119.

Åström, L. (2012). Overview of relay services in Europe and REACH 112 Relay Services. Paper presented at the Reach 112, Final conference. Retrieved from: http://www.reach112.eu/ressource/static/files/r112_final_conf_overview_relay_s ervices_lisa_omnitor.pdf

Baraldi, C., \& Gavioli, L. (2012). (Eds.). Coordinating participation in dialogue interpreting. Amsterdam: John Benjamins.

Batterbury, S. (2012). Language justice for sign language peoples: The UN Convention on the Rights of People with Disabilities. Language Policy, 11, 253272.

Bower, K. (2015). Stress and burnout in video relay service (VRS) interpreting. Journal of Interpretation, 24(1), Article 2. Retrieved from: http://digitalcommons.unf.edu/joi/vol24/iss1/2

Braun, S. (2013). Keep your distance? Remote interpreting in legal proceedings: A critical assessment of a growing practice. Interpreting, 15(2), 200-228.

Braun, S. \& Taylor, J. (2011). Video-mediated interpreting: an overview of current practice and research. In , S. Braun \& J. Taylor (Eds.), Videoconference and remote interpreting in criminal proceedings (pp.33-68). Guildford: University of Surrey. Retrieved from: http://www.videoconference-interpreting.net/Braun Taylor2011/03_Braun_Taylor_current_pr_res.pdf

Brunson, J. L. (2011). Video relay service interpreters. Washington: Gallaudet University Press.

CSMG (Oct, 2012). International developments of video relay services. OFCOM Final report. Retrieved from: http://stakeholders.ofcom.org.uk/binaries/research/ telecomsresearch/video-relay-services-2012.pdf

de Wit, M. (2012). Sign language interpreting in Europe. Create Space. Baarn: Maya de Wit. Retrieved from: http://www.tolkngt.nl/english/publicationsmore.html

FCC. (2016). Title IV of the Americans with Disabilities Act (Section 255). Federal Communications Commission. Retrieved 29 December 2016 from: https://www.fcc.gov/general/title-iv-ada.

Gracia-García, R. (2002). Telephone interpreting: A review of pros and cons. In S. Brennan (Ed.), Proceedings of the 43rd Annual Conference of the American Translators Association (pp. 195-216). Alexandria, VA: American Translators Association.

Gile, D. (1995). Basic concepts and models for interpreter and translator training. Amsterdam/Philadelphia: John Benjamins.

Hale, S. B. (2004). The discourse of court interpreting: Discourse practices of the law, the witness and the interpreter. Philadelphia: John Benjamins.

Hale, S., \& Napier, J. (2013). Research methods in interpreting: A Practical Resource. London: Bloomsbury.

Haualand, H. M. (2012). Interpreting ideals and relaying rights: A comparative study of video interpreting services in Norway, Sweden and the United States. Unpublished doctoral dissertation, University of Oslo.

Ladd, P. (2003). Understanding Deaf culture: In search of Deafhood. Clevedon, England: Multilingual Matters.

Leeson, L. (2005). Making the effort in simultaneous interpreting: Some considerations for signed language interpreters. In T. Janzen (Ed.), Topics in sign language interpreting (pp.51-68). Amsterdam: John Benjamins.

Leeson, L., Napier, J., Skinner, R., Lynch, T., Venturi, L. \& Sheikh, H. (2017). Conducting research with deaf sign language users. In J. McKinley \& H. Rose 
(Eds.), Doing research in applied linguistics: Realities, dilemmas, and solutions (pp.134-145). London: Routledge.

Lewin, D., Glennon, B., \& Hoemburg, B. (2009). Voice telephony services for deaf people: An independent report for Ofcom. Retrieved from: www.ofcom.org.uk/ research/telecoms/reports/voice_telep/voice_telep.pdf

Lucas, C., Bayley, R., \& Valli. C. (2001). Sociolinguistic variation in American Sign Language. Washington, DC: Gallaudet University Press.

Moser-Mercer, B. (2003). Remote interpreting: assessment of human factors and performance parameters. Retrieved from: http://aiic.net/page/1125/remoteinterpreting-assessment-of-human-factors-and-performanceparameters/lang/1

Napier, J. (2012). Exploring themes in stakeholder perspectives of video remote interpreting in court. In C. J. Kellett (Ed.), Interpreting across genres: Multiple research perspectives (pp. 219-254). Trieste: EUT Edizioni Universtà di Trieste.

Napier, J. (2013). "You get that vibe": A pragmatic analysis of clarification and communicative accommodation in legal video remote interpreting. In L. Meurant, A. Sinte, M. Van Herreweghe \& M. Vermeerbergen (Eds.), Sign language research uses and practices: Crossing views on theoretical and applied sign language linguistics (pp. 85-110). Nijmegen, The Netherlands: De Gruyter Mouton and Ishara Press.

Napier, J., \& Leeson, L. (2016). Sign language in action. London: Palgrave.

Napier, J., \& Leneham, M. (2011). "It was difficult to manage the communication": Testing the feasibility of video remote signed language interpreting in court. Journal of Interpretation, 21(1), 52-63.

Napier, J., Skinner, R. \& Turner, G. H. (in press). Enabling political participation through video remote interpreting: A case study. In J. Napier, R. Skinner \& S. Braun (Eds.), Here or there? Research on interpreting via video link. Washington. Washington DC: Gallaudet University Press.

NCIEC (2008). Steps toward identifying effective practices in VRS interpreting. Report from the Interpreting via Video Work Team. Retrieved from: http://www.nciec.org/projects/docs/Steps_VRS 2008Report.pdf.

Nicodemus, B., Swabey, L. \& Taylor, M. (2014). Preparation strategies used by American Sign Language-English interpreters to render President Barack Obama's inaugural address. The Interpreter's Newsletter, 19, 27-44.

Quinto-Pozos, D., Casanova de Canales, K., \& Treviño, R. (2010). Trilingual video relay service (VRS) interpreting in the United States . In R. L. McKee \& J. Davis (Eds.), Interpreting in multilingual, multicultural contexts (pp. 28-54). Washington, DC: Gallaudet University Press.

Padden, C. \& Humphries, T. (1988) Deaf in America: Voices from a culture. Cambridge, MA: Harvard University Press.

Palmer, J. L., Reynolds, W., \& Minor, R. (2012). "You want what on your pizza!?" Videophone and video-relay service as potential influences on the lexical standardization of American Sign Language. Sign Language Studies, 12(3), 371397.

Power, M. R., Power, D., \& Horstmanshof, L. (2006). Deaf people communicating via SMS, TTY, relay service, fax, and computers in Australia. Journal of Deaf Studies and Deaf Education, 12(1), 80-92.

Power, D. J., Power, M. R., \& Rehling, B. (2007). German deaf people using text communication: Short message service, TTY, relay services, fax, and e-mail. American Annals of the Deaf, 152(3), 291-301.

RID (2007). Video relay service interpreting: Standard practice paper. Retrieved from: https://drive.google.com/file/d/0B3DKvZMflFLdNE1zZGRPdDN4NGM/view

Roberson, L, Russell, D., \& Shaw, R. (2011). American Sign Language/English

interpreting in legal settings: Current practices in North America. Journal of Interpretation, 64-79.

Roberson, L, Russell, D., \& Shaw, R. (2012). A case for training signed language interpreters for legal specialization. International Journal of Interpreter Education, 4(2), 52-73. 
Rosenstock, R. (2016). Comprehension of expository International Sign. In R. Rosenstock \& J. Napier (Eds.), International Sign: Linguistic, usage and status issues (pp. 84-102). Sociolinguistics of Deaf Communities Series. Washington, DC: Gallaudet University Press.

Rosenstock, R. \& Napier, J. (2016). To International Sign or not to International Sign? That is the question. In R. Rosenstock \& J. Napier (Eds.), International Sign: Linguistic, usage and status issues. Sociolinguistics of Deaf Communities Series (pp. 1-14). Washington, DC: Gallaudet University Press.

Roy, C. B. (2000). Interpreting as a discourse process. New York: Oxford University Press.

Rozinger, I., \& Shlesinger, M. (2010). Much ado about something remote: Stress and performance in remote interpreting. Interpreting, 12(2), 214-147.

Russell, D. (2008). Interpreter preparation conversations: Multiple perspectives. In D. Russell \& S. Hale (Eds.), Interpreting in legal settings (pp. 123-147). Washington, DC: Gallaudet University Press.

Salaets, H. \& Böser, U. (2015). Surveys: Co-Minor/ Interpreting with children in investigative interviews. Paper presented at the CTISS-ARTIS Justisigns Symposium Interpreter-mediated justice: Different languages, different research methodologies, Heriot-Watt University, Edinburgh, Scotland, 7 November 2015.

Schembri, A., \& Johnston, T. (2013). Sociolinguistic variation and change in sign languages. In R. Bayley, R. Cameron, \& C. Lucas (Eds.), The Oxford Handbook of Sociolinguistics. DOI: 10.1093/oxfordhb/9780199744084. 013.0025.

Senghas, R. J., \& Monaghan, L. (2002). Signs of their times: Deaf communities and the culture of language. Annual Review of Anthropology, 31, 69-97.

Simon, J., Hollrah, B., Lightfoot, M., Laurion, R., \& Johnson, L. (2010). Steps toward identifying effective practices in video remote interpreting. Retrieved from: http://www.interpretereducation.org/wpcontent/uploads/2011/06/VRIStepsRepor tApril2010_FINAL1.pdf

Skinner, R., Napier, J., \& Braun, S. (in press). Remote interpreting: A mapping of the field. In J. Napier, R. Skinner \& S. Braun (Eds.), Here or there? Research on interpreting via video link. Washington DC: Gallaudet University Press.

Turner, G. H. (1995). The bilingual, bimodal courtroom: A first glance. Journal of Interpretation 7(1), 3-34.

Turner, G. H. (2007). Professionalisation of interpreting with the community: Refining the model. In C. Wadensjö, B. E., Dimitrova, \& A. L., Nilsson (Eds.), The Critical Link 4: Professionalisation of interpreting in the community (pp. 181192). Amsterdam: John Benjamins.

Turner, G. H. (2006). "I'll tell you later": On institutional audism. Deaf Worlds, 22(3), 24-35.

Turner, G. H., Napier, J., Skinner, R., \& Wheatley, M. (2016). Telecommunication relay services as a tool for deaf political participation and citizenship. Information, Communication \& Society, 20(10), 1521-1538.

Vogler, C., McWhinney, J., Harper, P., Raike, A., Hellström, G., \& Vanderheiden, G. (2011, November). Video relay service practices and policies around the world. Proceedings of the International AEGIS Conference, Brussels, Belgium.

Wadensjö, C. (1998). Interpreting as interaction. London: Palgrave.

Warnicke, C., \& Plejert, C. (2012). Turn-organisation in mediated phone interaction using Video Relay Service (VRS). Journal of Pragmatics, 44, 1313-1334.

Wessling, D. \& Shaw, S. (2014). Persistent emotional extremes and Video Relay Service interpreters. Journal of Interpretation, 23(1), Article 6. Retrieved from: http://digitalcommons.unf.edu/joi/vol23/iss1/6

Wheatley, M. (2014). Best practice example: Insign project - improving communication between deaf and hard of hearing persons and the EU institutions. In A. Pabsch (Ed.), UNCRPD implementation in Europe - A Deaf perspective (pp.89-96). Brussels, Belgium: European Union of the Deaf. 